\title{
Cellular mechanisms of inflammation- meeting held in Liège, Belgium, 12 September 1997
}

\section{Organized by G. Camus}

Centre Interdisciplinaire de Biochimie de l'Oxygène, Institut de Chimie, B6, Sart Tilman, 4000 Liège,

Belgium

Tel: (+32) 43663360

Fax: (+32) 43662866

\section{Ramipril prevents endothelial dysfunction induced by oxidized LDL}

\section{G. Berkenboom, I. Langer, A. El Ajani, Y. Carpentier and J. Fontaine}

Cardiology Department, Erasme Hospital, Route de Lennik, 808, 1070 Brussels, Belgium

Oxidized (ox) LDL plays a key role in hypercholesterolaemia-induced impairment of endothelium-derived (ED) NO-mediated responses. To assess whether long-term ACE inhibition may prevent this $\mathrm{E}$ dysfunction, four groups of rats were treated in parallel; Group 1 (Ram 10) received ramipril $10 \mathrm{mg} /$ $\mathrm{kg} /$ day p.o. for 6 weeks; Group 2 (Ram + HOE) received ramipril $10 \mathrm{mg} / \mathrm{kg} /$ day p.o. for 4 weeks and the last 2 weeks a cotreatment with ramipril plus HOE140 (a bradykinin $B_{2}$ antagonist $500 \mu \mathrm{g} / \mathrm{kg} /$ day, subcutaneous injections); Group 3 (Ram 1) received ramipril $1 \mathrm{mg} / \mathrm{kg} /$ day p.o. for 6 weeks; Group 4 served as control. Rings of thoracic aorta from these groups were contracted by phenylephrine (Phe) and relaxations to acetylcholine (Ach, $10 \mathrm{nM}$ to $0.1 \mathrm{mM}$ ) were determined in the absence (oxLDL-) and in the presence (oxLDL+) of human $\mathrm{Cu}^{2+}$-oxidized LDL $(300 \mu \mathrm{g} / \mathrm{ml}, 30 \mathrm{~min}$ preincubation).

\begin{tabular}{|c|c|c|c|}
\hline \multirow[t]{2}{*}{ Groups } & \multirow{2}{*}{$\begin{array}{c}\text { Maximal } \\
\text { response (\%) } \\
\text { oxLDL- oxLDL+ }\end{array}$} & \multicolumn{2}{|c|}{ Area under curve } \\
\hline & & oxLDL- & oxLDL+ \\
\hline $\begin{array}{l}\text { Ram } 10(\boldsymbol{n}=9) \\
\operatorname{Ram}+\operatorname{HOE}(\boldsymbol{n}=9) \\
\operatorname{Ram} 1(\boldsymbol{n}=12) \\
\text { Control }(\boldsymbol{n}=12)\end{array}$ & $\begin{array}{ll}97 \pm 2^{*} & 93 \pm 5 \\
82 \pm 3 & 48 \pm 3 \S \\
91 \pm 4^{*} & 76 \pm 7 \S \\
82 \pm 4 & 53 \pm 5 \S\end{array}$ & $\begin{array}{l}358 \pm 19 * \\
284 \pm 10 \\
289 \pm 20 \\
269 \pm 15\end{array}$ & $\begin{array}{l}369 \pm 22 \\
165 \pm 9 \S \\
250 \pm 32 \\
202 \pm 17 \S\end{array}$ \\
\hline
\end{tabular}

(mean $\pm \mathrm{SEM}) ; \%$ of Phe-induced plateau; ${ }^{*} P<0.05$ vs. control; $\S P$ $<0.05$ vs. oxLDL-
The toxic effect of ox LDL is directly related to the NO synthase pathway as L-arginine $(0.1 \mathrm{mM})$ coincubated with oxLDLcomple tely prevented the Edysfunction in control group. Aortic cyclicGMP content, reflecting $\mathrm{NO}$ availability, was significantly increased in Ram 10 (by $76 \%$ vs control) but not in the other groups. Thus, long-term ACE inhibition dose-dependently protects against the acute toxicity of oxLDL; the mechanism is bradykinin-dependent and seems to involve an upregulation of $\mathrm{EDNO}$ synthase pathway via $\mathrm{B}_{2}$ kinin receptor.

\section{Endotoxaemia and production of TNF- $\alpha$ induced by strenuous physical exercise in man}

G. Camus, M. Nys, J. Poortmans, I. Venneman, T. Monfils, G. Deby-Dupont, A. Juchmès-Ferir, C. Deby, M. Lamy and J. Duchateau

FNRS, Center for the Biochemistry of Oxygen, Institute of Chemistry, Sart Tilman, University of Liège, Belgium

To examine whether endotoxaemia accompanying strenuous physical work is involved in exerciseinduced increase in plasma tumour necrosis factor alpha (TNF- $\alpha$ ), 14 male recreational athletes [mean age: $28 \pm 1$ (SEM) years] were studied. Exercise consisted of a $1.5 \mathrm{~km}$ river swim, a $40 \mathrm{~km}$ bicycle race, and a $10 \mathrm{~km}$ road race. Mean time to complete the race was $149.8 \pm 4.8$ ( \pm SEM) min (range: $128-195 \mathrm{~min})$. The plasma concentrations of TNF- $\alpha$ were significantly higher than baseline values immediately after exercise and $1 \mathrm{~h}$ later $(P<0.001)$. This variable returned to prerace levels the day after exercise. Marked, transient decreases in the plasma levels of anti-lipopolysaccharide (LPS) IgG and IgM antibodies primarily directed against a panel of Gram-negative LPSs were observed after the race. An inverse, highly significant relation- 
ship between the increase in plasma TNF- $\alpha$ concentrations and the changes in circulating anti-LPS $\operatorname{IgM}$ antibodies was found $(r=-0.7 ; P<0.01)$. This finding strongly argues for the involvement of endotoxaemia in the exercise-induced production of TNF- $\alpha$ observed in our subjects.

\section{Interleukin-10 treatment of lipopolysaccharide-activated macrophages improves control of Trypanosoma cruzi infection by enhancing nitric oxide release}

\section{F. Jacobs, ${ }^{1}$ D. Chaussabel, ${ }^{1}$ C. Truyens, ${ }^{2}$ V. Leclerq, ${ }^{1}$ Y. Carlier, ${ }^{2}$ M. Goldman ${ }^{1}$ and B. Vray ${ }^{1}$}

${ }^{1}$ Laboratoire d'Immunologie Expérimentale,

Faculté de Médecine, Université Libre de Bruxelles, route de Lennik 808, 1070 Brussels;

${ }^{2}$ Laboratoire de Parasitologie, Faculté de

Médecine, Université Libre de Bruxelles,

Belgium

Trypanosoma cruzi, a protozoan parasite, is the aetiological agent of Chagas' disease. Murine macrophages infected by T. cruzi trypomastigotes, release nitric oxide (NO) when suitably activated. Several studies have indicated the involvement of $\mathrm{NO}$ in the control of T. cruzi infection. Interleukin 10 (IL-10) is a polyfunctional cytokine with various properties and produced by several cell types including macrophages. To date, relationships between IL-10, macrophage activation by lipopolysaccharide (LPS) and T.cruzi infection are still unclear. In this study, we demonstrated that, in LPS-activated and T. cruziinfected macrophages, the addition of murine recombinant IL-10 increased the NO production and resulted in a better control of T. cruzi infection. In addition, endogenous IL-10 produced by $T$. cruziinfected mouse peritoneal macrophages participate in the NO production since neutralization of endogenous IL-10 by specific monoclonal antibodies inhibits NO release. Taken together, these data highlight the activating role of IL-10 on LPS-activated macrophages through a NO-mediated control of T. cruzi infection.

\section{Critical role of reactive oxygen intermediates (ROI) in TNF- $\alpha$ and IL-10 production after liver cold ischaemia and reperfusion in mice}

O. Le Moine, H. Louis, P. Stordeur, J. M. Collet, M. Goldman and J. Devière

Departments of Gastroenterology and

Immunology, Hospital Erasme. ULB, Brussels

and Laboratory of Organic Chemistry, Faculté

de Médecine, Université de Mons-Hainaut,

Belgium

ROI, cytokines and adhesion molecules are released and expressed by the liver during experimental and human liver transplantation. They play a role in liver cell damage and in the recruitment of inflammatory and immunocompetent cells that might eventually lead to graft dysfunction and rejection. To date, the stimuli leading to cytokine release are unknown. The aim of the present study was to assess the role of ROI in cytokine release by the ischaemic liver after reperfusion and its modulation by exogenous administration of IL-10. In that setting we developed an endotoxinfree isolated perfused mouse liver system. Liver injury was assessed by the release of ALT in the liver effluent. Cytokines were measured by commercially available kits and mRNA by RT-PCR After increasing cold ischaemic times, both TNF, IL-10 and IFN- $\gamma$ are released after reperfusion of the organ (peak levels after $75 \mathrm{~min}$ ). At the gene level, mRNA expression for these cytokines was increased only after reperfusion. Two antioxidants, N-acetylcysteine (NAC) and allopurinol significantly decreased TNF and IL-10 release $(-64 \%$ $62 \%$ and $-49 \%-57 \%$ respectively), as did an inhibitor of the transcription factor NF-kB mobilization $(-73 \%$ and $-76 \%$ for TNF and IL-10, respectively). Liver injury was also significantly decreased by these compounds. In addition, non-ischaemic livers submitted to an oxidant stress by hydrogen peroxide released both TNF and IL-10, an effect abolished by concomitant infusion of NAC. Finally, recombinant IL-10 (rIL-10) added during reperfusion of ischaemic livers was able to abolish TNF and IFN- $\gamma$ release and decrease liver injury. In conclusion, ROI are involved in cytokine release after reperfusion of ischaemic livers. Both antioxidants, inhibitors of NF $\mathrm{kB}$ mobilization and rIL10 are able to dampen cytokine production and liver injury. This may represent a new therapeutic modality in transplantation medicine.

\section{Protection of alveolar type II cells by perflubron against mediators of inflammation}

\section{Mathy-Hartert, ${ }^{1}$ G. Deby-Dupont, ${ }^{1,2}$ C. Deby ${ }^{1}$ and M. Lamy ${ }^{1,2}$}

${ }^{1}$ Centre for the Biochemistry of Oxygen, Institut de Chimie, B6a, Sart Tilman, 4000, Liège;

${ }^{2}$ University Hospital Centre, University of Liège, Sart Tilman, 4000, Liège, Belgium

Perfluorocarbons (PFC) are liquids with high $\mathrm{O}_{2}$ dissolving capacity and low surface tension. These properties led to the utilization of PFC for liquid ventilation in lung pathologies such as acute respiratory distress syndrome (ARDS) where PFC supported gas exchange and reduced surface tension at the alveolar air liquid interface. ARDS is accompanied by acute inflammatory process, where excessive polymorphonuclear (PMN) activation is responsible for lung injury. We investigated the biocompatibility of 
perfluorooctylbromide (PFOB) with cultured human epithelial alveolar cells (A549 line). Confluent cells were overlayed with $\mathrm{PFOB}$, covered with cultured medium and incubated at $37^{\circ} \mathrm{C}$ for time periods ranging from $1 \mathrm{~h}$ to $17 \mathrm{~h}$. Incorporation of PFOB into the cells was investigated by gradient density centrifugation and a cytotoxicity index (CI) was estimated from the release of pre-incorporated ${ }^{51} \mathrm{Cr}$. No incorporation of $\mathrm{PFOB}$ was obtained (cell density was not increased) and no cytotoxicity of PFOB was observed. To test the cytoprotective effects of PFOB against mediators of inflammation, PMN were isolated from whole blood and activated by phorbol myristate acetate (PMA) $\left(10^{-6} \mathrm{M}\right)$. PFOB-overlayed cells were covered with HBSS + albumine $0.1 \%$ containing supernatant of activated PMN or activated PMN and were incubated for $3 \mathrm{~h}$ at $37^{\circ} \mathrm{C}$. A cell ratio (PMN/ A549) of 10 was used. Control incubations were performed with alveolar cells without PFOB. Supernatant of activated PMN induced a weak cytotoxicity $(\mathrm{CI}=24.4 \pm 5.4 \%)$ which was largely reduced in the presence of PFOB $(\mathrm{CI}=8.6 \pm 3.2 \%)$. Activated $\mathrm{PMN}$ induced a higher cytotoxicity $(\mathrm{CI}=78.0 \pm 8.3 \%)$ which was not significantly reduced by $\mathrm{PFOB}(\mathrm{CI}=$ $72.4 \pm 7.2 \%$ ). In conclusion, $\mathrm{PFOB}$ was innocuous for cells and did not enter the cells. PFOB protected the alveolar cells against oxidative stress induced by the supernatant of activated PMN, but could not efficaciously protect against a large number of stimulated PMN.

\section{Antioxidant activity of propofol: chemiluminescence study and cytoprotection}

\section{Mathy-Hartert, ${ }^{1}$ G. Deby-Dupont, ${ }^{1}$ P. Hans ${ }^{2}$ and M. Lamy ${ }^{2}$ \\ ${ }^{1}$ Centre de Biochimie de l'Oxygène, Université de Liège B6a Sart Tilman 4000 Liège; ${ }^{2}$ Service d'Anesthésie-Réanimation, CHU, B35 Sart Tilman 4000 Liège, Belgium}

The anaesthetic agent propofol (PPF) has been reported to possess an in vitro antioxidant activity as efficient as that of $\alpha$-tocopherol (vitamin E). We studied the effects of PPF on in vitro lipoperoxidation induced by three free radical systems (hydroxyl, ferryl and oxo-ferryl radicals). Lipoperoxidation was quantified by gas chromatography measurement of pentane released from linoleic acid decomposition. We also separately examined the effects of PPF, Diprivan ${ }^{\circledR}$ (the commercial form of the drug) and intralipid (IL) (the vehicle of PPF in Diprivan ${ }^{\circledR}$ ) on the luminol enhanced chemiluminescence (CL) of stimulated human neutrophils or endothelial cells. Finally, we tried the effects of Diprivan ${ }^{\circledR}$ in the protection of endothelial cells against oxidant stress induced by the myeloperoxidase $/ \mathrm{H}_{2} \mathrm{O}_{2} / \mathrm{Cl}^{-}$system. PPF inhibited lipoperoxidation in a dose-dependent manner, and its antioxidant activity was similar to that of vitamin E. Both compounds were however more active against hydroxyl radical induced lipoperoxidation. The CL of $5 \times 10^{5}$ polymorphonuclear neutrophils (PMN) stimulated by $10^{-6}$ Mphorbol myristate ace tate (PMA) was inhibited similarly by Diprivan ${ }^{\circledR}$ and IL, but not in a dose-dependent manner. On the contrary, PPF inhibited CL in a dose dependent manner: $37.3 \pm 6.3$ \%inhibition was obtained with $5 \times 10^{-5} \mathrm{MPPF}$ a dose corresponding to a clinically relevant concentration. The CL of $5 \times 10^{5}$ endothelial cells was also inhibited by PPF, Diprivan ${ }^{\circledR}$, and to a lesser extent by IL. These antioxidant properties of PPF were correlated with protection of endothelial cells submitted to an oxidant stress. PPF thus exerts a high antioxidant capacity, that cannot impair the intracellular phagocytic cell functions of PMN because PPF did not enter into the cells (HPLC measurement after extraction).

\section{Ceftazidime reduces free radicals formation by alveolar cells submitted to anoxia and reoxygenation}

\author{
A. Mouithys-Mickalad, ${ }^{1}$ M. Mathy-Hartert, ${ }^{1}$ \\ G. Deby-Dupont, ${ }^{1,2}$ C. Deby ${ }^{1}$ and M. Lamy ${ }^{1,2}$ \\ ${ }^{1}$ Centre for the Biochemistry of Oxygen, \\ Institute of Chemistry, B6a, Domaine \\ Universitaire du Sart Tilman, 4000 Liège; \\ ${ }^{2}$ Department of Anaesthesiology and Intensive \\ Care, Centre Hospitalier Universitaire, B35, \\ Domaine Universitaire du Sart Tilman, 4000, \\ Liège, Belgium
}

Cultured cells have been shown to generate active oxygen species (AOS) during anoxia-reoxygenation sequence. Electron spin resonance (ESR) spectroscopy with alpha-(4-pyridyl-oxide)-N-tert-butylnitrone $(4-\mathrm{POBN})$ spin trapping, in the presence of ethanol, was used to monitor over time the AOS, especially lipid-derived free radicals, formed by cultured human alveolar type II cells (A549) exposed (at $\left.37^{\circ} \mathrm{C}\right)$ to anoxia $\left(\mathrm{N}_{2}, 1 \mathrm{~h}\right)$ and reoxygenenation $\left(\mathrm{O}_{2}\right.$, or under ambient air in HBSS). We investigated the effects of ceftazidime (CAZ), a third generation cephalosporin antibiotic which was demonstrated to protect endothelial cells submitted to $\mathrm{NaOCl}$-oxidant stress, ${ }^{1}$ to inhibit lipid peroxidation ${ }^{2}$ and desactivate singlet oxygen. ${ }^{3}$ We also compared the effects of CAZ with those of superoxide dismutase (SOD), TIRON (4,5-dihydroxy-1, 3-benzene-disulfonic acid) a specific reagent for $\mathrm{O}_{2}^{-\mathrm{o}}$ scavenging, and L-NMMA (an NO synthase inhibitor). The reaction between AOS or lipid radicals and ethanol leads to ethoxy free radicals, which then react with 4-POBN to form specific spin adducts (POBN-EtOH). Anoxied alveolar cells pro- 
duced AOS. This production increases with the reoxygenation time and the ESR spectra show that the following hyperfin splittings obtained from experimental ESR spectra $\left(\mathrm{a}_{\mathrm{N}}=15.7 \mathrm{G}\right.$ and $\left.\mathrm{a}_{\mathrm{H}}=2.7 \mathrm{G}\right)$ are in agreement with the data of literature. ${ }^{4}$ When SOD $(200 \mathrm{U} / \mathrm{ml})$ was added before anoxia-reoxygenation, the ESR signal was decreased (37\% of inhibition) versus control (alveolar cells alone). Likew ise, the ESR signal intensity was reduced when cells were incubated in the presence of either CAZ $(2 \mathrm{mM} ; 37 \%$ of inhibition) or TIRON $(0.1 \mathrm{mM} ; 67 \%$ of inhibition $)$ as well as L-NMMA ( $1 \mathrm{mM}$; $43 \%$ of inhibition). TIRON could be a better inhibitor because it enters inside the cells. CAZ and L-NMMA do not enter the cells and react with free radicals outside. Our ESR results demonstrate that CAZ thus reduces the free radical formation, confirming the quenching effect on AOS we recently reported.,

\section{References}

1. Mathy-Hartert M, et al. Mediators Inflamm 1995; 4: 437-443.

2. Mathy-Hartert M, et al. Intensive Care Med 1994; 5 (2suppl): 74

3. Deby-Dupont et al. Biochem Biophys Acta (1997).

4. Connor HD, et al. Transplantation 1992; 54: 199-204.

\section{Technical development towards the microdialysis monitoring of cytokines in the brain extracellular space during ischaemic insult}

\section{Olislagers, ${ }^{1}$ S. Goldman, ${ }^{2}$ M. A. Laute, ${ }^{1}$ S. Blecic, ${ }^{1}$ M. Goldman ${ }^{3}$ and S. Dethy ${ }^{1}$} ${ }^{1}$ Laboratoire de Neurochime Clinique (Service de Neurologie); ${ }^{2}$ Unité TEP-Cyclotron Biomédical; ${ }^{3}$ Service d'Immunologie, Université Libre de Bruxelles-Hôpital Erasme, 808 route de Lennik, 1070 Bruxelles, Belgium

TNF- $\alpha$ has unpredictable neurodestructive or neuroprotective effects on the ischaemic neuron. To better define the influence of cytokines during brain ischaemia, we should access the kinetics of their concentration in the brain extracellular space (EC) where they interact with neuronal and glial receptors. The microdialysis (MD) technique allows such an EC monitoring of bioactive molecules. To test the $\mathrm{MD}$ technique for the detection of TNF- $\alpha$ EC changes in response to brain insult, we have developed a model of LPS injection in the rat striatum. Two MD probes (CMA 12, $100 \mathrm{kDa}$ ) were inserted in the right (LPS) and left (PBS) striatum. Previous experiments have shown that TNF- $\alpha$ EC concentration determined by this technique in intact rat striatum (no injection) was $100 \mathrm{pg} / \mathrm{ml}$. Samples were collected every $60 \mathrm{~min}$ for $7 \mathrm{~h}$ and TNF- $\alpha$ levels were determined by ELISA. MD demonstrated progressive increase of TNF- $\alpha$ EC con- centration in the right striatum from 5 to $7 \mathrm{~h}$ after LPS injection $(n=10$, ANOVA $P<0.0001)$ reaching a maximum value of $666 \pm 239 \mathrm{pg} / \mathrm{ml}$ at $7 \mathrm{~h}$ postinjection. This value was $120 \%$ higher than in the control PBS-injected striatum. The technique will now be applied to the monitoring of TNF- $\alpha$ EC concentration in the rat brain after ischaemic insult produced by middle cerebral artery occlusion.

\section{Plasmatic myeloperoxydase (MPO) level in horses with strangulated intestinal obstruction}

\section{Serteyn, ${ }^{1}$ S. Grulke, ${ }^{1}$ H. Benbarek, ${ }^{1}$ M. Mathy-Hartert, ${ }^{2}$ G. Deby-Dupont, ${ }^{2}$ C. Deby ${ }^{2}$ and M. Lamy ${ }^{2}$ \\ ${ }^{1}$ Anesthésiologie Générale, Clinique et \\ Pathologie Chirurgicale des Grands Animaux, Université de Liège, B41 4000 Sart Tilman; ${ }^{2}$ Centre de Biochimie de I'Oxygène, Université de Liège, B6a 4000 Sart Tilman, Belgium}

In equine pathology, mortality associated with intestinal strangulation in horses usually ranges between $50 \%$ and $80 \%$ The intestinal injury that develops during strangulation may progress after detorsion due to irreversible cellular alterations that occurred during the ischaemic period, or due to exacerbation of cellular injury as a result of the cascade of events initiated on reperfusion. Myeloperoxidase is a specific azurophilic granule enzyme from neutrophils. It produces oxidant species that can induce high cellular toxicity. It is released in plasma when neutrophils degranulate and is thus a witness of neutrophil activation. We used an original specific technique (radioimmunoassay) for measurement of the levels of myeloperoxidase in horses operated for intestinal obstruction; 15 horses were operated for a large intestine obstruction: nine horses with nonstrangulated obstruction (control group) and six with strangulated obstruction leading to severe complication and death (strangulated group). MPO was measured at reception (P1), at time of surgery and intensive care (P2), at the phase of recuperation or complication (P3). Mean MPO values were higher in strangulated group for the three phases: $243 \mathrm{ng} / \mathrm{ml}$ at $\mathrm{P} 1,426 \mathrm{ng} / \mathrm{ml}$ at $\mathrm{P} 2$ and $379 \mathrm{ng} / \mathrm{ml}$ at $\mathrm{P} 3$ compared to 122,169 and $107 \mathrm{ng} / \mathrm{ml}$ for P1, P2 and P3 respectively in control group $(P<0.01$ for $\mathrm{P} 2$ and $\mathrm{P} 3$ between the two groups).

The significant difference of plasmatic MPO values demonstrated a neutrophil activation that could be explained by an endotoxin release by the ischaemic bowel. This high leukocyte activation could thus contribute to the development of an oxidative stress during equine acute abdomen. 
Reactive oxygen intermediates increase the production of IL-8 by human dendritic cells

\section{Verhasselt, C. Buelens, F. Willems and $\mathbf{M}$. Goldman \\ Laboratory of Experimental Immunology, U.L.B., Campus Erasme, 808, route de Lennik, 1070 Brussels, Belgium}

Reactive oxygen intermediates (ROI) are commonly produced during inflammatory processes as well as during postischaemic reperfusion. Besides their cytotoxic effects, ROI also affect cell functions by modifying their redox potential and/or by activating transcription factors. We studied the effects of $\mathrm{H} 202$, a major source of ROI, on human dendritic cells
(DC). Dose-response experiments showed that the optimum concentration of $\mathrm{H} 202$ was $100 \mu \mathrm{M}$. At this concentration, $\mathrm{H} 202$ stimulated the production of high concentrations of IL-8 $(6 \mathrm{ng} / \mathrm{ml})$ and increased but to a lesser extent the production of TNF- $\alpha$ $(0.4 \mathrm{ng} / \mathrm{ml})$ by DC. $\mathrm{H} 202$ did not affect their production of IL-6, IL-12 and IL-10. When we looked at the effects of $\mathrm{H} 202$ on the expression of surface molecule of DC, we showed that $\mathrm{H} 202$ moderately increased their expression of HLA-DR and decreased their expression of B7-1 and CD40. H202 did not modify significantly neither B7-2 nor CD54 expression. From these data, we might extrapolate that DC which play critical role in the induction of specific immune responses are also involved in inflammation by amplifying the recruitment of neutrophils through IL-8 synthesis. 


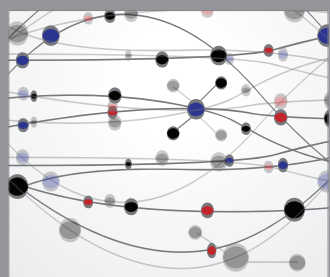

The Scientific World Journal
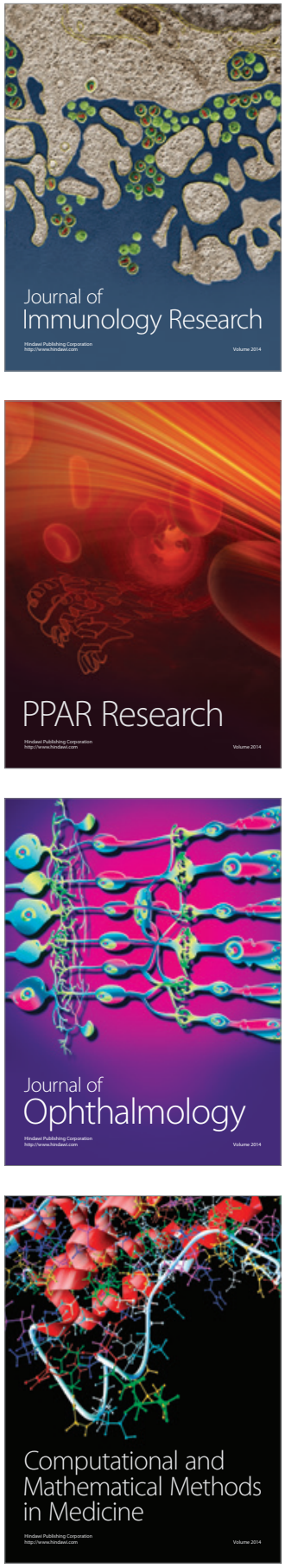

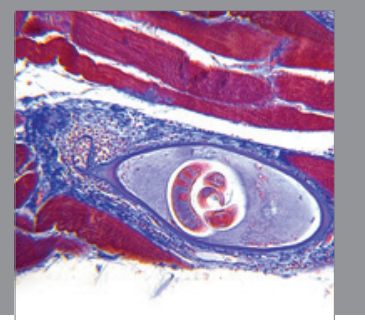

Gastroenterology

Research and Practice
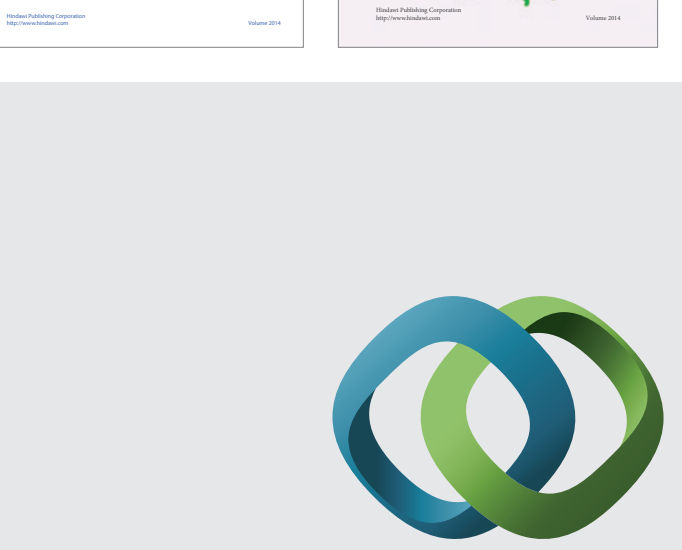

\section{Hindawi}

Submit your manuscripts at

http://www.hindawi.com
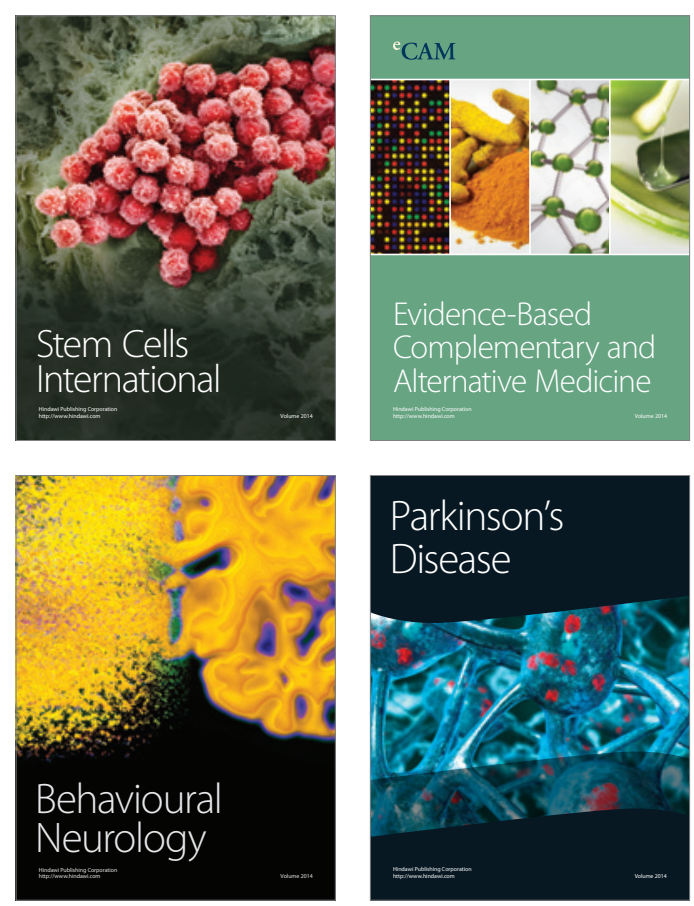

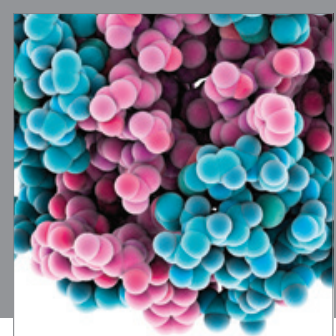

Journal of
Diabetes Research

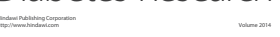

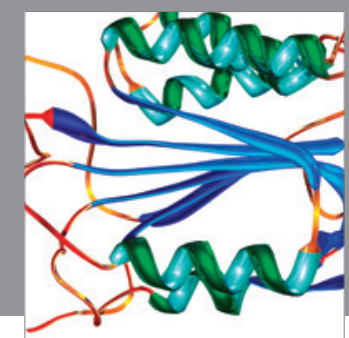

Disease Markers
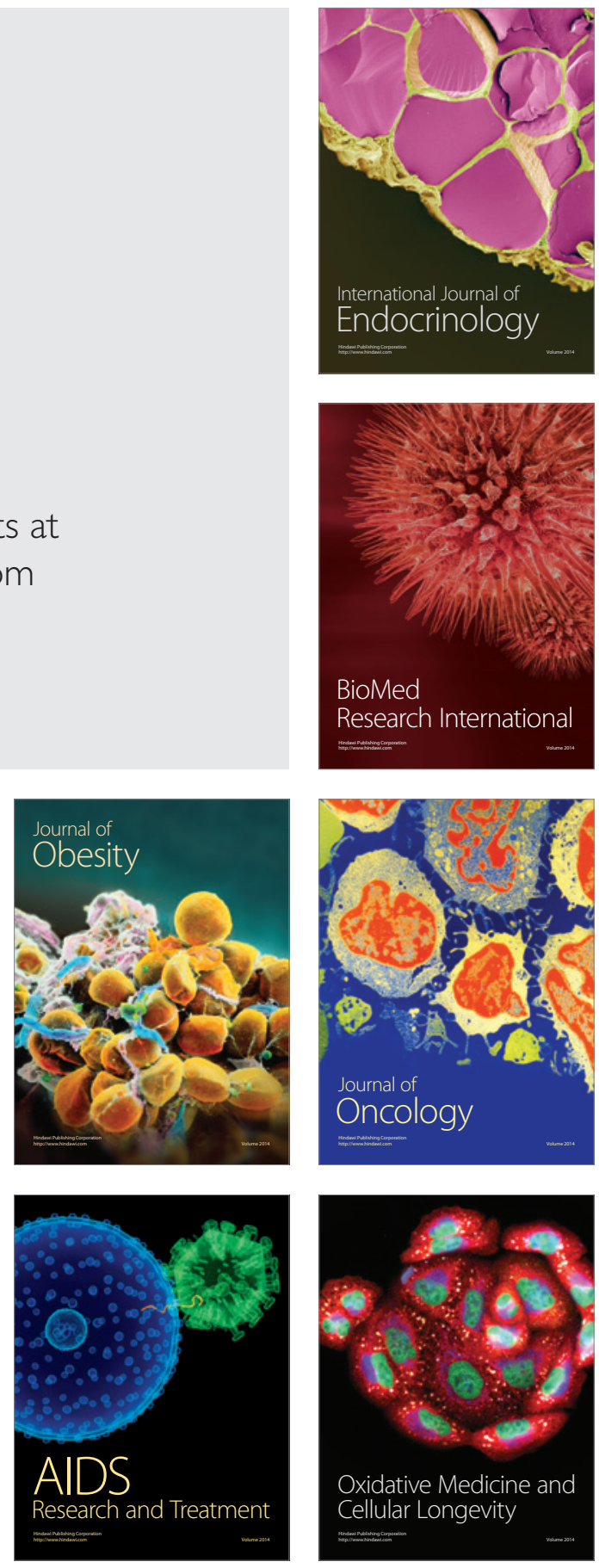